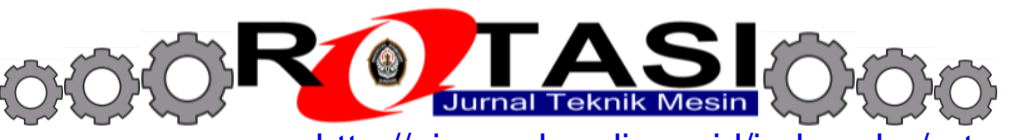

Available online at Website http://ejournal.undip.ac.id/index.php/rotasi

\title{
PENGARUH TEMPERING DAN PERUBAHAN STRUKTUR MICRO BAHAN CHAIN-PIN PADA DRAG CHAIN- COVEYOR BATU BARA
}

\author{
Gunawan Dwi Haryadi \\ Dosen Jurusan Teknik Mesin, Fakultas Teknik, Universitas Diponegoro \\ J1. Prof. Sudharto, SH., Tembalang-Semarang 50275, Telp. +62247460059 \\ E-mail: gunawan_dh@yahoo.com
}

\begin{abstract}
Drag Chain Conveyor merupakan alat transport material yang konstruksinya seperti rantai dan di antara pasangan mata rantai (chain link) terdapat penghalang yang berfungsi mendorong material pada lintasannya. Karena penggunaan yang terus menerus maka membutuhkan komponen perakitan yang memerlukan taraf keselamatan yang tinggi. Penelitian ini bertujuan untuk mengetahui karakterisasi awal komposisi bahan paduan dan perlakuan panas yang dapat mempengaruhi sifat-sifat bahan. Objek penelitian adalah Chain-pin yang merupakan salah satu komponen penting dalam rangkaian chain-link. Hasil uji komposisi dan pengujian SEM terhadap perubahan sifat-sifat mekanis dan perubahan struktur mikro yang dihasilkan dari proses tempering menjadi fokus utama dalam penelitian ini. Hasil karakterisasi awal chain-pin yaitu fasa martensit temper, ferit, sementit, juga terlihat pengerasan permukaan, korosi, porositas dan kluster martensit. Fenomena yang terjadi setelah proses tempering adalah ukuran batas butir chain pin yang semakin membesar dan semakin kasar, nilai kekerasan chain pin menurun dan keuletan meningkat. Dari pengamatan SEM tidak terlihat adanya retak mikro pada chain pin.
\end{abstract}

Keywords: chain-pin, chain-link, drag chain conveyor, SEM

\section{PENDAhuluan}

Drag Chain Conveyor adalah alat pembawa material yang konstruksinya seperti rantai dimana di antara pasangan mata terdapat drag yang berfungsi mendorong material pada lintasannya [1]. Penggunaan rutin dalam suatu material terutama pada chain-pin yang merupakan komponen penting drag chain conveyor yang berfungsi mengantarkan batubara dari feed bin ke coal mill tentunya memerlukan bahan yang kuat dan tahan lama [2]. Dalam memenuhi kebutuhan dan mengetahui karakter bahan yang digunakan sebagai alat transport batubara maka diperlukan penelitian sifat mekanik komponen chain-pin.

Bahan tidak selalu bebas dari tegangan internal yang tertinggal, yaitu tegangan sisa (residual stress), yang merupakan tegangan yang tersisa dalam bahan tanpa adanya gaya-gaya dari luar. Proses tempering merupakan salah satu usaha untuk meminimumkan pengaruh tegangan sisa melalui usaha penyegaran bahan agar efek tegangan sisa tidak signifikan. Penelitian ini juga membahas pengaruh proses tempering pada peregangan kristal baja chain pin akibat perlakuan waktu dan variasi temperatur tempering [3].

Dalam pembuatan material dengan sistem berpasangan, satu part memiliki sifat dipertahankan dan part lain memiliki kecenderungan untuk dikorbankan. Pertimbangan ini diambil karena apabila part berpasangan diciptakan dengan karakter material yang sama kelunakannya maka bisa terjadi weldeffect, namun apabila sama kekerasannya akan memberikan sliding force yang kecil tapi memerlukan proses lebih lanjut dan biayanya juga akan lebih mahal [4]. Biasanya part yang dikorbankan adalah bagian yang mudah dibentuk dengan kontur sederhana. Namun pada kenyataannya chain-link dengan kontur yang lebih rumit dari pada chain-pin justru patah lebih awal daripada chain-pin saat pengopersian

Besarnya regangan mikro bisa didapat dengan metode non destructive dan destructive. Regangan mikro yang terjadi biasanya dipengaruhi oleh perlakuan panas dengan temperatur tinggi yang dapat mengubah struktur mikro serta struktur kristalnya. Terdapat berbagai fenomena yang disebabkan oleh perlakuan panas pada material, yang dapat bertujuan untuk menambah atau mengurangi sifat bahan sesuai dengan kebutuhan dari penggunaan material tersebut [5]. Bahan tidak selalu bebas dari tegangan internal yang tertinggal, yaitu tegangan sisa (residual stress), yang merupakan tegangan yang tersisa dalam bahan tanpa adanya gaya-gaya dari luar. Ada beberapa usaha untuk meminimumkan pengaruh tegangan sisa, salah satunya adalah proses tempering melalui usaha penyegaran bahan agar efek tegangan sisa tidak signifikan [5].

Penelitian ini dilakukan untuk menginvestigasi permasalahan tentang mutu bahan yang ada sekaligus untuk mengetahui karakteristik chain-pin dari sudut pandang metalurgi dan mengetahui pengaruh struktur mikro serta sifat mekanis terhadap perlakuan tempering. Pengujian komposisi paduan dan struktur mikro chain-pin sebelum dan sesudah proses tempering dilakukan di penelitian ini. Tujuan lainnya adalah mengidentifikasi jenis material chain-pin dalam katalog logam standar agar mudah mencari material pengganti chain-pin dan dapat mengetahui fenomena tempering chain-pin terhadap struktur mikro, sifat mekanis terhadap variasi temperatur tempering. Identifikasi retak mikro yang 
mungkin terjadi karena tempering juga dibahas dan dieveluasi dalam penelitian ini. Karakterisasinya dilakukan untuk mencari bahan struktur yang dapat digunakan sebagai komponen perakitan drag chain conveyor yang memerlukan taraf keselamatan yang tinggi. Adapun pengujian yang dilakukan adalah sifat mekanis, kekerasan, SEM dan struktur mikro dalam material chain-pin.

\section{MATERIAL DAN METODOLOGI}

Metode penelitian yang digunakan adalah true experiment research, dalam hal ini seluruh kegiatan penelitian dilakukan di laboratorium dengan pengujian komposisi paduan, pengujian struktur mikro, SEM, proses perlakuan tempering, dan pengujian kekerasan. Langkah-langkah kegiatan penelitian yang dilakukan dapat dilihat pada flowchart Gambar 1.

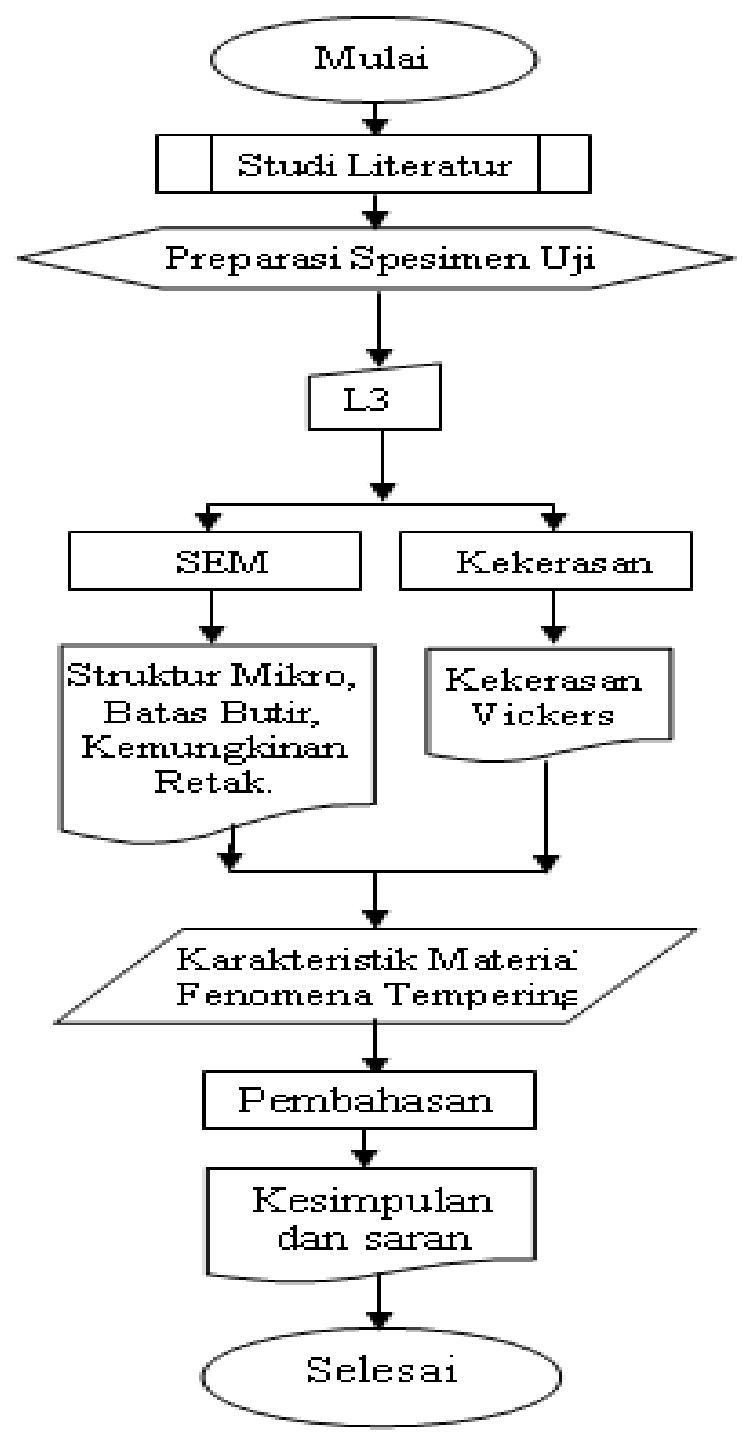

Gambar 1. Diagram alir penelitian.

Langkah-langkah dalam penelitian yang pertama adalah studi literatur dilakukan untuk mencari materi dan teori yang berhubungan dengan penelitian ini dan memudahkan dalam menentukan proses yang akan dilakukan selama penelitian. Materi yang dibutuhkan antara lain perlakuan panas, uji struktur mikro mikroskop optik, uji nilai kekerasan Micro Vickers dan SEM.

Langkah preparasi spesimen uji yang dilakukan adalah persiapan material mengambil material dari pabrik semen terkemuka di Indonesia berupa chain-pin dan dibuat standar untuk pengujian kekerasan vickers, SEM dan metallography.

Dalam keterangan simbol L3, langkah tersebut menjelaskan proses perlakuan material tanpa treatment dan proses tempering dengan variasi temper $250^{\circ} \mathrm{C}, 350^{\circ} \mathrm{C}, 450^{\circ} \mathrm{C}, 550^{\circ} \mathrm{C}$ dan $650^{\circ} \mathrm{C}$ pada chain-pin. Tujuannya 
mengidentifikasi jenis material chain-pin, mengetahui fenomena tempering chain-pin terhadap struktur mikro, sifat mekanis terhadap variasi temperatur tempering.

Dalam langkah pengujian material, pengujian yang dilakukan yaitu pengujian SEM dan kekerasan vickers. Pengujian SEM meliputi metallography, batas butir dan kemungkinan retak. Karakterisasinya dilakukan untuk mencari bahan struktur yang dapat digunakan sebagai komponen perakitan drag chain conveyor yang memerlukan taraf keselamatan yang tinggi.

\section{HASIL DAN PEMBAHASAN}

3.1 Pengujian metalography chain-pin surface tanpa perlakuan panas.

Hasil pengujian metalography Chain-Pin Surface tanpa perlakuan pada chain-pin dapat dilihat pada Gambar 2.

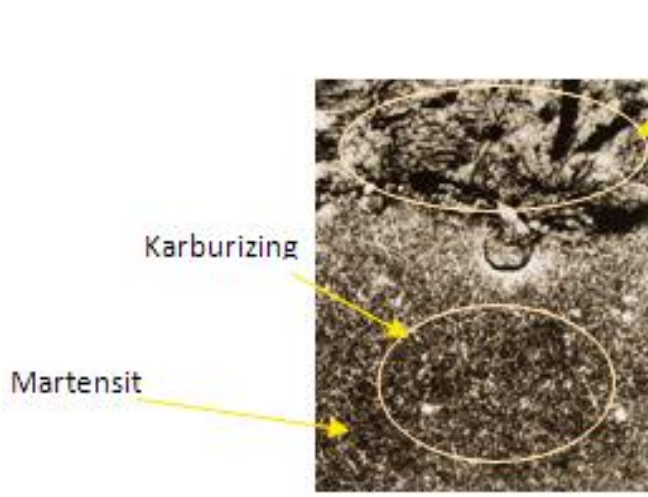

(a)

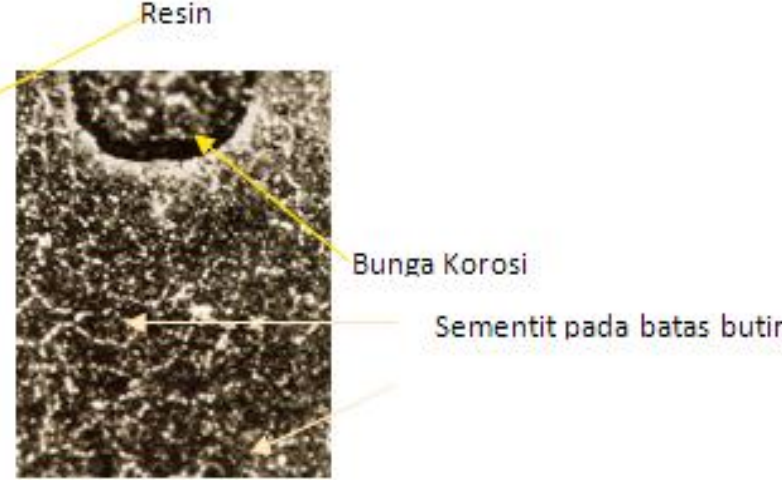

(b)

Gambar 2. Topografi Chain-Pin Surface dengan perbesaran (a) 180x(b) 720x

Gambar 2 merupakan gambar topografi Chain-Pin Surface. Pin Surface yang terlihat pada Gambar 2 (a) batas butir belum terlihat jelas, sedangkan Gambar 2 (b) sudah terlihat. Dari gambar tersebut dapat diketahui bahwa permukaan chain pin sudah mengalami korosi yang ditunjukkan dengan gambar bunga korosi yang bentuknya seperti cekungan atau benjolan. Setelah dianalisa bahwa korosi yang terjadi disebabkan oleh pengaruh batu bara yang diangkut yang bersifat korosif. Chain-pin juga mengalami pengerasan permukaan karburizing yang ditunjukkan dengan daerah yang lebih gelap tepat dibawah resin karena kadar karbon yang meningkat. Proses karburizing ini akan mengakibatkan chain-pin menjadi keras pada permukaannya sehingga bersifat tahan terhadap beban fatique dan memiliki wear ability yang tinggi, serta bersifat tangguh pada bagian dalamnya agar dapat menjaga agar tidak retak karena tegangan sisa tekan antara surface dan core [6].

Chain-pin memiliki kandungan karbon $0,93704 \%$ pada bagian permukaan terkarburizing dan kandungan karbon sedang pada bagian dalamnya. Pada permukaan martensit yang terbentuk adalah martensit campuran dan pada bagian dalam martensit yang terbentuk adalah martensit lath. Dari data yang diperoleh dapat diketahui bahwa $\mathrm{M}_{\mathrm{s}}$ pada permukaan terbentuk pada $126,09^{\circ} \mathrm{C}$ sedangkan untuk bagian dalamnya chain pin diketahui bahwa $\mathbf{M}_{\mathrm{s}}$ terbentuk $298,19^{\circ} \mathrm{C}$. Dari perhitungan dapat dilihat bahwa bagian chain pin yang lebih cepat terjadi perubahan dari austenit menjadi martensit pada saat di lakukan quenching adalah bagian core karena bagian ini memiliki $\mathrm{M}_{\mathrm{s}}$ yang lebih tinggi dari pada bagian surface. Namun karena diinginkan chain-pin juga memiliki sifat tangguh maka dilakukan perlakuan panas untuk meningkatkan sifat ketangguhannya dengan tempering [7].

\subsection{Hasil Pengujian Metalografi Pin Mid (bagian tengah) Tanpa Perlakuan}

Gambar 3 merupakan gambar topografi core chain-pin perbesaran (a)180X (b) $720^{\circ} \mathrm{C}$. Dari Gambar 3 dapat diketahui bahwa core chain-pin merupakan martensit dan martensit yang terbentuk adalah martensit lath. Dari gambar dapat diketahui bahwa martensit yang terbentuk adalah martensit lath. Gambar putih menunjukkan campuran antara ferit dan karbida besi sementit namun pada perbesaran 180X belum terlihat jelas perbedaannya. Gambar area hitam pekat yang tidak merata menunjukkan cluster martensit karena adanya imperfect persebaran karbon saat casting material. Ini akan berpengaruh pada kekerasan material yang tidak merata. Pada perbesaran 720X juga dapat diketahui bahwa struktur mikro chain-pin mid adalah martensit lath yang telah mengalami tempering. Dan juga terlihat adanya ferrit dan partikel karbida (sementit) yang terbentuk pada batas butir. Martensit ditunjukkan dengan bagian warna hitam kasar. 


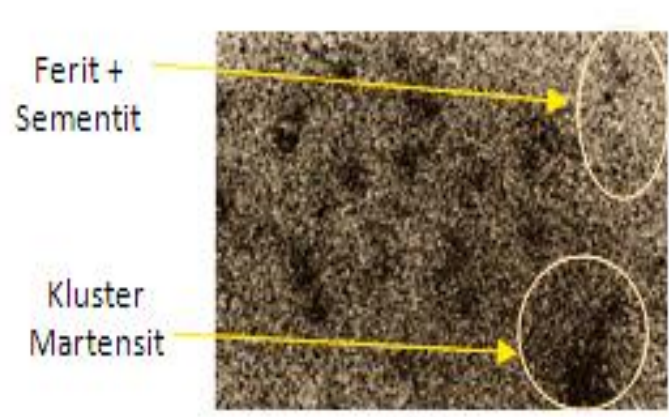

(a)

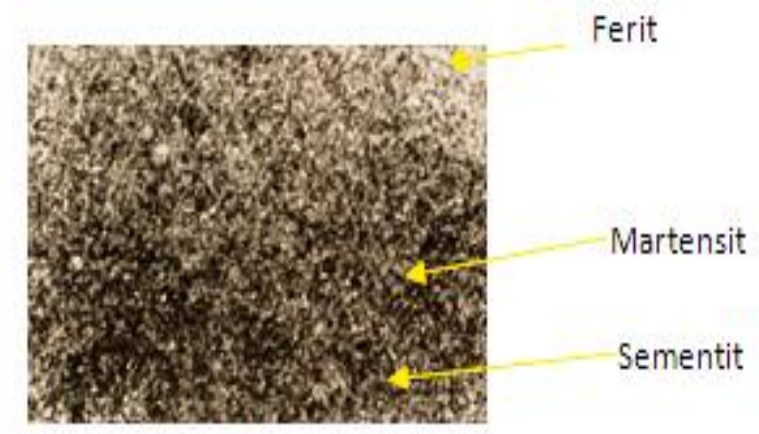

(b)

\section{Gambar 3. Topografi Chain-Pin mid (bagian tengah) dengan perbesaran (a)180x (b)720x. \\ 3.3 Pengujian SEM Chain-Pin Surface Tanpa Perlakuan}

Hasil SEM Chain-Pin tanpa perlakuan pada bagian permukaan dapat dilihat pada Gambar 4. Pada Gambar 4, topografi chain-pin permukaan pada pembesaran 500x batas butir sudah terlihat jelas yang digambarkan dengan garis putih yang membentuk area. Terlihat adanya inklusi mulai pada perbesaran 500x namun lebih jelasnya dapat diamati pada perbesaran 3000x. Korosi pada permukaan chain-pin tidak terlihat seperti pada pengamatan mikroskopis, hal ini menunjukkan bahwa hanya sebagian kecil permukaan chain pin yang mengalami korosi sehingga korosi yang terjadi tidak berpengaruh banyak terhadap sifat permukaan. Pada perbesaran 500x juga terlihat adanya daerah yang lebih gelap yang menunjukkan adanya konsentrasi karbon lebih banyak dari pada daerah core yang diakibatkan oleh proses karburizing. Seperti dijelaskan pada pengujian metalography [8].

Tampilan bintik-bintik putih yang tersebar mengindikasikan karbida yang tersebar yang berasal dari elemenelemen paduan pembentuk karbida. Karena proses karburizing ini pada chain-pin surface cenderung memiliki martensit dalam bentuk campuran dan lebih keras dari pada martensit bagian core chain-pin.

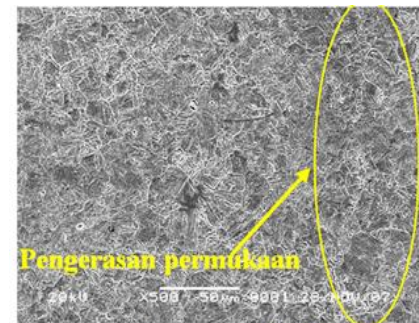

Perbesaran 500X

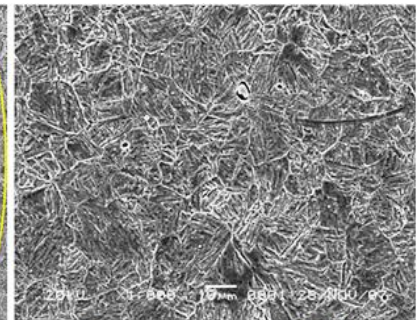

Perbesaran $1000 \mathrm{X}$

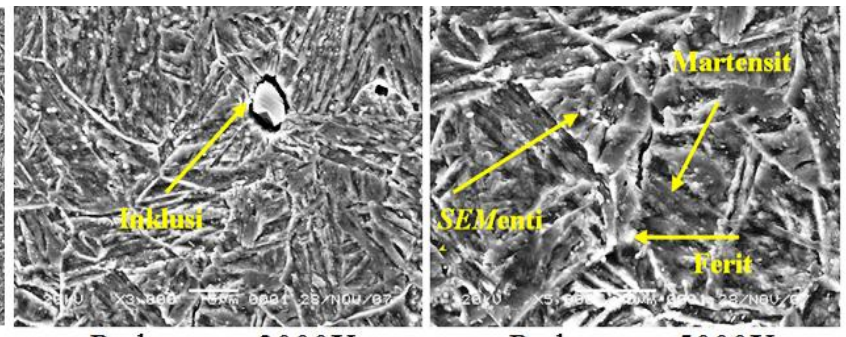

Perbesaran $3000 \mathrm{X}$
Perbesaran $5000 \mathrm{X}$

Gambar 4. Hasil SEM Chain-Pin Surface tanpa perlakuan.

\subsection{Pengujian SEM Chain-Pin Mid (Bagian Tengah) Tanpa Perlakuan}

Gambar 5 adalah topografi chain-pin core pada 500x batas butir sudah terlihat jelas yang digambarkan dengan garis putih yang membentuk area-area dan terlihat adanya porositas. Topografi porositas ini dapat kita lihat dengan jelas pada perbesaran 5000x. Pada perbesaran 500x terlihat adanya daerah yang lebih gelap yang menunjukkan adanya kluster martensit yang lebih gelap, hal ini bisa diakibatkan karena persebaran karbon yang kurang sempurna pada proses casting sehingga pada saat dilakukan quench muncul kluster martensit seperti pada gambar dan hal ini dapat mengakibatkan pada karateristik kekerasan chain-pin yang tidal linear dari luar ke dalam.

Kluster martensit ini lebih terlihat jelas pada pengujian metalografi. Martensit yang terbentuk pada surface dan core chain-pin memiliki struktur yang berbeda. Pada core chain-pin memiliki kandungan karbon yang lebih rendah dari permukaan sehingga martensit yang terbentuk cenderung martensit Lath [9]. 


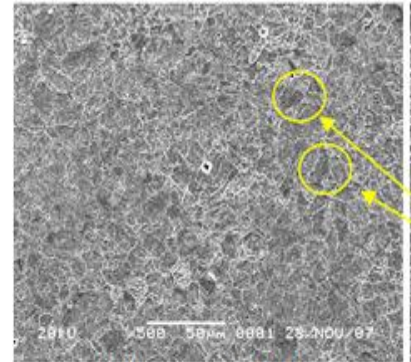

Perbesaran 500X

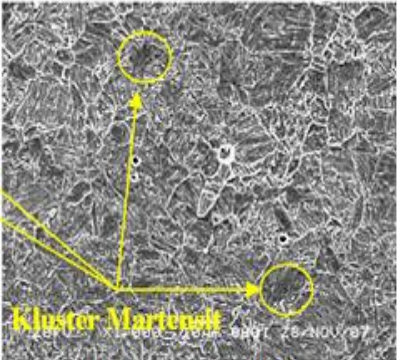

Perbesaran 1000X

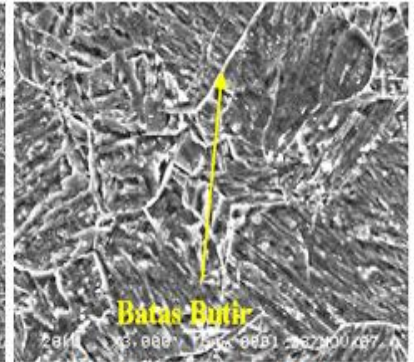

Perbesaran 3000X

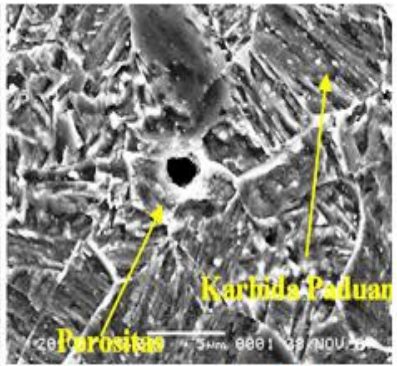

Perbesaran 5000X

Gambar 5. Hasil SEM Chain Pin Mid tanpa perlakuan.

\subsection{Pengujian SEM Chain-Pin Mid (bagian tengah) Perlakuan Temper $250^{\circ} \mathrm{C}$}

Hasil pengujian SEM Chain-Pin Mid (bagian tengah) perlakuan temper $250^{\circ} \mathrm{C}$ dapat dilihat pada Gambar 6. Hasil pengamatan pada temperatur $250^{\circ} \mathrm{C}$ ini terlihat adanya porositas karena udara yang terperangkap saat casting. Penemperan pada temperatur ini batas butir terlihat lebih kasar dari sebelum di temper, hal ini terjadi karena proses mengendapnya elemen paduan seperti nickel, silikon, aluminium, mangan secara halus pada matriks ferrite pada batas butir yang akan meningkatkan kekerasan ferit dan mulai tumbuhnya karbida transisi. Namun penggetasan tidak terjadi karena kandungan elemen pendukung fenomena tersebut sangat kecil sehingga tidak terjadi [10].

Tidak terjadinya fenomena penggetasan ini dapat dibuktikan dengan penurunan kekerasan chain-pin pada temperatur ini. Pada temperatur ini martensit memiliki ikatan atom karbon cukup kuat sehingga tidak terjadi transformasi martensit dan hanya mulai tumbuhnya karbida transisi [10].

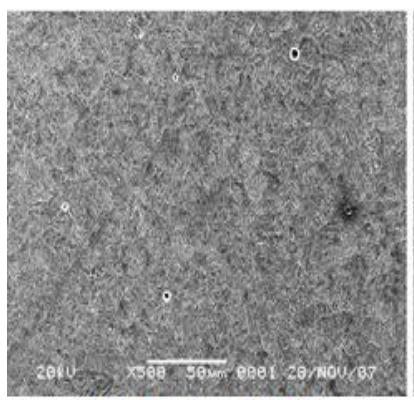

Perbesaran 500X

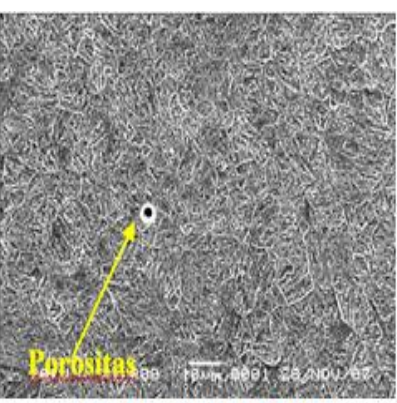

Perbesaran 1000X

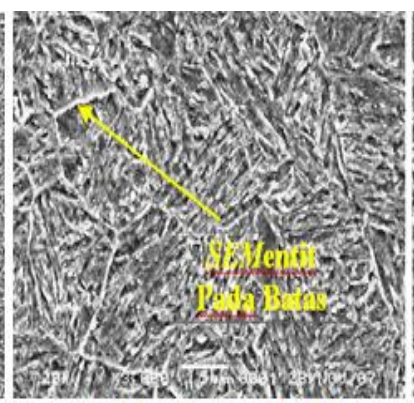

Perbesaran 3000X

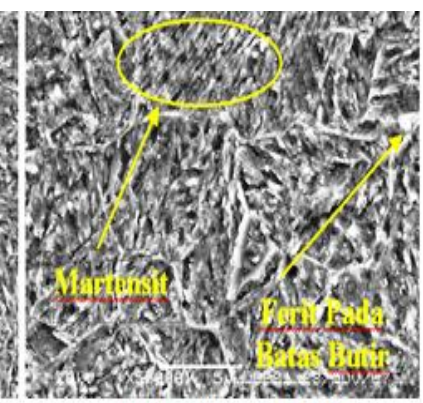

Perbesaran 5000X

\section{Gambar 6. SEM Chain Pin Mid perlakuan temper $250^{\circ} \mathrm{C}$}

\subsection{Pengujian SEM Chain-Pin Mid (bagian tengah) Perlakuan Temper $350^{\circ} \mathrm{C}$}

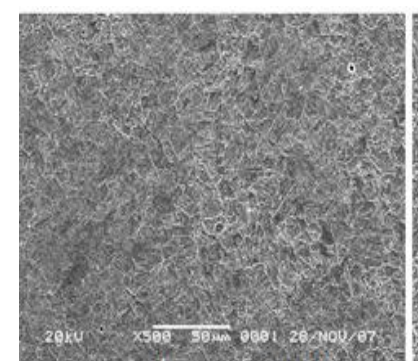

Perbesaran 500X

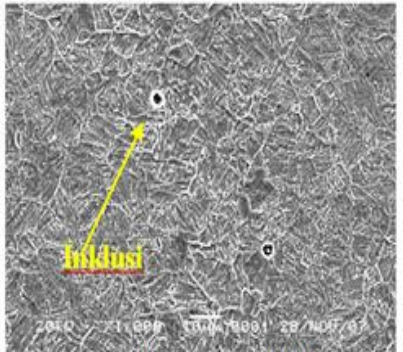

Perbesaran 1000X

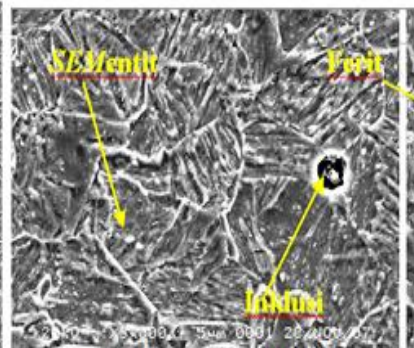

Perbesaran $3000 \mathrm{X}$

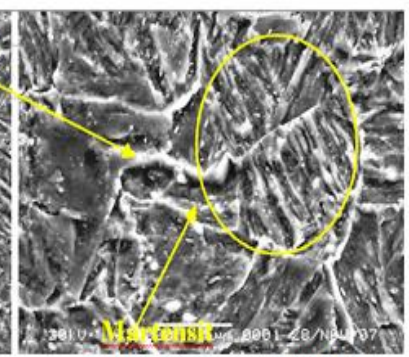

Perbesaran 5000X

Gambar 7. Hasil SEM Chain Pin Mid perlakuan temper $350^{\circ} \mathrm{C}$.

Hasil pengamatan di temperatur $350^{\circ} \mathrm{C}$ pada Gambar 7 juga terlihat porositas karena udara yang terperangkap saat casting. Pada temperatur ini mulai terjadi transformasi martensit menjadi ferit dan SEMentit. Selain itu juga terlihat batas butir yang dikarenakan adanya transformasi SEMentit dan ferit dari martensit. Sementit cenderung bertransformasi pada batas butir dan berbentuk bulatan lebih terang, sedangkan ferit yang terbentuk cenderung agak tersebar dengan ukuran yang lebih besar dari sementit dan berwarna agak abu-abu, serta hitam kusam berbentuk seperti jarum untuk martensit. Walaupun batas butir membesar namun tampilannya tidak sekasar penemperan temperatur $250^{\circ} \mathrm{C}$, hal ini dikarenakan pada temperatur $350^{\circ} \mathrm{C}$ elemen paduan seperti molybdenum, vanadium, niobium, dan chromium larut dari batas butir shingga terlihat lebih halus [10]. 
3.7 Pengujian SEM Chain-Pin Mid (bagian tengah) Perlakuan Temper $450^{\circ} \mathrm{C}$

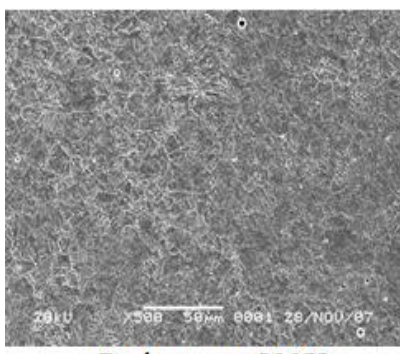

Perbesaran 500X

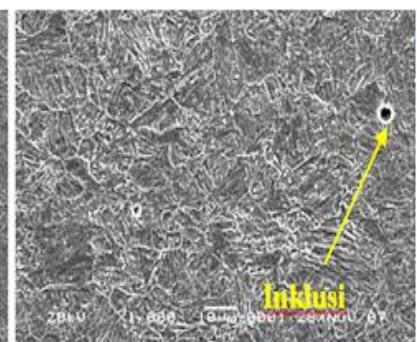

Perbesaran 1000X

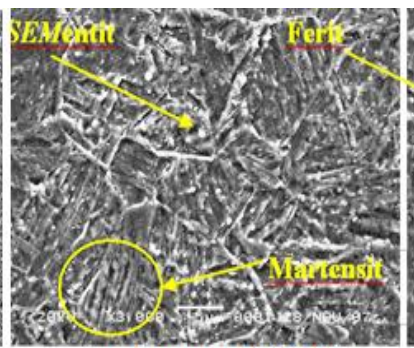

Perbesaran $3000 \mathrm{X}$

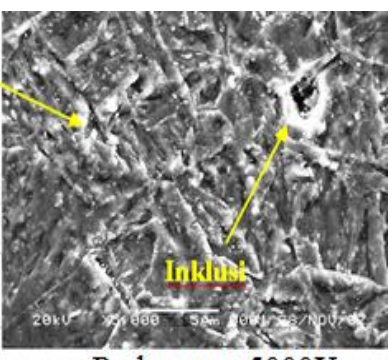

Perbesaran 5000X

\section{Gambar 8. Hasil SEM Chain Pin Mid perlakuan temper $450^{\circ} \mathrm{C}$}

Hasil pengamatan pada temperatur $450^{\circ} \mathrm{C}$ dapat dilihat pada Gambar 8. Dari Gambar 8 juga terlihat adanya porositas karena udara yang terperangkap saat casting. Penemperan pada temperatur ini terjadi transformasi lebih lanjut martensit menjadi ferit dan sementit lebih lanjut. Selain itu sementit yang terbentuk pada temperatur $350^{\circ} \mathrm{C}$ sudah mengalami pertumbuhan yang semakin membesar yang terlihat dari batas butir yang semakin membesar dan lebih kasar dari pada penemperan temperatur $350^{\circ} \mathrm{C}$ yang diakibatkan sementit dan ferit yang mulai tumbuh karena transformasi martensit. Sementit cenderung terletak pada batas butir dan berwarna lebih terang, sedangkan ferit tersebar dengan ukuran lebih besar dari sementit dan berwarna abu-abu, serta hitam berbentuk jarum: martensit [11].

\subsection{Pengujian SEM Chain-Pin Mid (bagian tengah) Perlakuan Temper $550^{\circ} \mathrm{C}$}

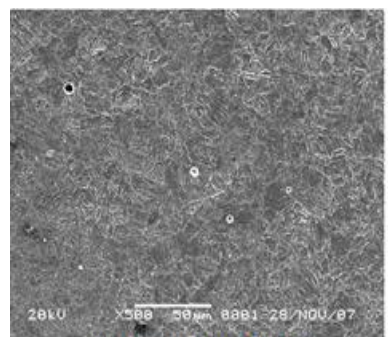

Perbesaran 500X

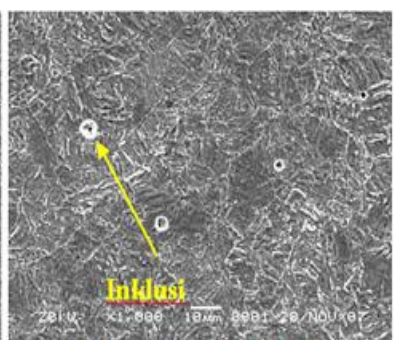

Perbesaran 1000X

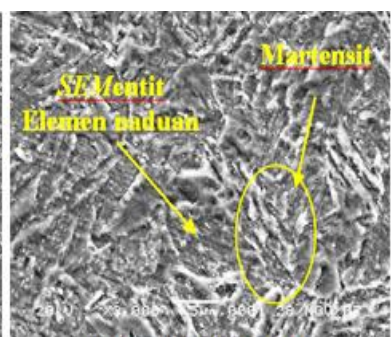

Perbesaran 3000X

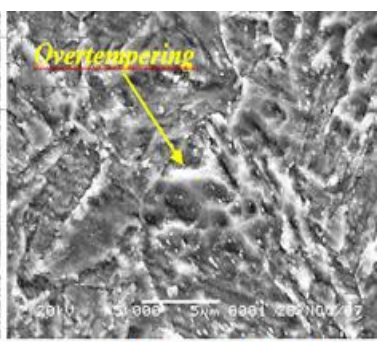

Perbesaran 5000X

Gambar 9. Hasil SEM Chain Pin Mid perlakuan temper $550^{\circ} \mathrm{C}$

Hasil pengamatan pada temperatur $550^{\circ} \mathrm{C}$ seperti Gambar 9 ini masih terlihat porositas karena udara yang terperangkap saat casting. sementit yang tumbuh dengan mengambil karbon dari martensit tumbuh dengan mendesak batas butir, hal ini sangat merugikan karena akan meningkatkan keuletan berlebih (overtempering). Perlakuan tempering pada temperatur ini tidak berguna karena justru akan mengurangi sifat mekanis (kekerasan) dari chain-pin, kekerasannya semakin menurun. Hal ini Secondary Hardening tidak terjadi yang dikarenakan elemen paduan pendukung terbentuknya karbida seperti vanadium, titanium, tungsten, niobium, chromium, dan molybdenum kandunganya kurang memenuhi yaitu masih dibawah 0,5\% kecuali chromium [12].

\subsection{Pengujian SEM Chain-Pin Mid (bagian tengah) Perlakuan Temper $650^{\circ} \mathrm{C}$}

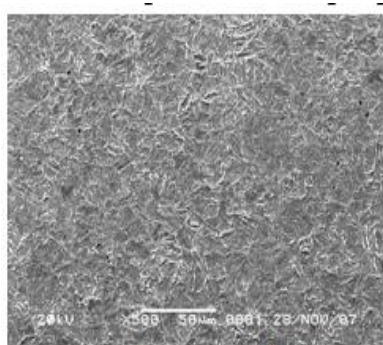

Perbesaran 500X

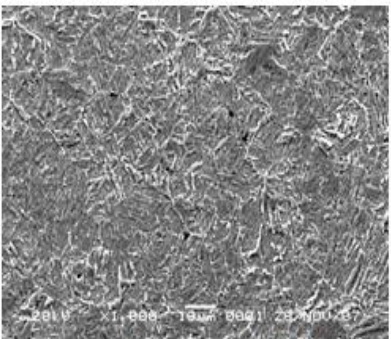

Perbesaran 1000X

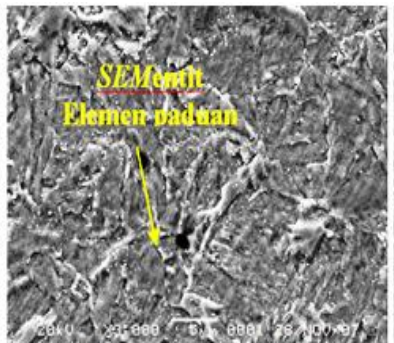

Perbesaran $3000 \mathrm{X}$

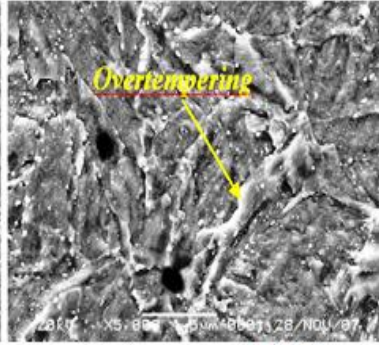

Perbesaran 5000X

Gambar 10. Hasil SEM Chain Pin Mid perlakuan temper $650^{\circ} \mathrm{C}$.

Hasil pengamatan pada Gambar 10 dengan temperatur $650^{\circ} \mathrm{C}$ ini juga masih terlihat adanya porositas karena inklusi udara yang terperangkap saat casting. Partikel karbida yang tumbuh dengan mengambil karbon dari martensit tumbuh dengan mendesak batas butir. Perlakuan tempering pada temperatur sama seperti pada temperatur $550^{\circ} \mathrm{C}$ tidak 
berguna karena justru akan mengurangi sifat mekanis dari chain-pin, kekerasannya semakin menurun (terjadi overtempering). Pada temperatur ini Secondary Hardening tidak terjadi karena elemen paduan pendukung terbentuknya karbida seperti vanadium, titanium, zirconium, tungsten, niobium chromium, dan molybdenum kandunganya kurang memenuhi yaitu masih dibawah $0,5 \%$ [13].

\subsection{Hasil pengujian Kekerasan Vickers}

Pada chain-pin sifat kekerasannya diperoleh dengan mengatur banyaknya martensit yang terbentuk setelah proses quenching. Sedangkan kekuatan diperoleh dengan mengatur pertumbuhan martensit menjadi ferit dan partikel karbida sementit. Pengerasan permukaan karburizing pada chain-pin menyebabkan permukaan chain-pin lebih keras daripada bagian dalamnya. Hal ini dapat dilihat dari pengujian dimana titik pengujian paling dekat permukaan memiliki nilai kekerasan yang paling besar apabila dibandingkan dengan titik-titik lainnya.

Dalam pengujian juga terjadi kekerasan yang tidak linear pada seluruh bagian chain-pin. Setelah dipelajari lebih lanjut maka yang terjadi adalah kurang sempurnanya proses pencampuran paduan saat pembuatan chain-pin, sehingga terdapat beberapa kluster martensit yang mengakibatkan bagian tersebut memiliki kekerasan yang lebih besar daripada daerah yang lain. Hal ini juga bisa terjadi karena proses karburizing yang menyebabkan kandungan karbon masuk lebih kedalam chain-pin dan membentuk kluster karbida [14].

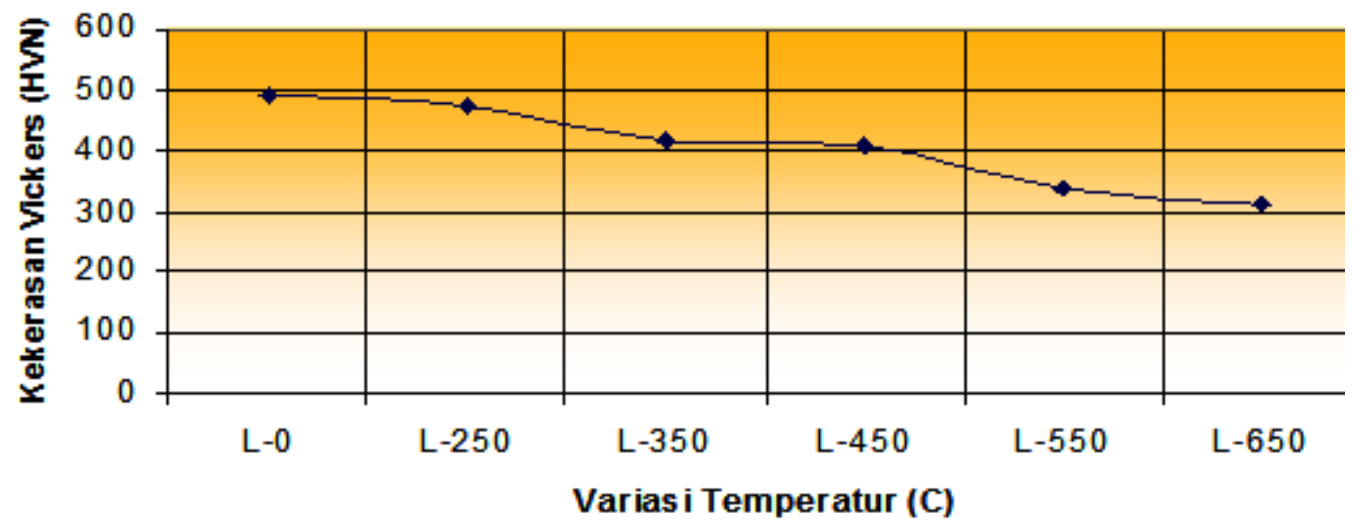

Gambar 11. Grafik gabungan HVN pada berbagai variasi temperature tempering.

Pengaruh perlakuan tempering terhadap nilai kekerasan chain-pin dapat dilihat pada Gambar 11. Dengan meningkatnya temperatur tempering akan menurunkan kekerasan chain-pin tetapi berkebalikan akan meningkatkan keuletan chain-pin. Keadaan tersebut juga diikuti dengan meningkatnya diagonal jejak indentor uji. Fenomena diatas terjadi karena adanya penurunan kadar karbon yang dimiliki martensit karena terjadi pertumbuhan partikel karbida sementit, semakin tinggi temperatur tempering akan meningkatkan pertumbuhan karbida sementit yang semakin lama akan menyebabkan adanya penggumpalan karbida yang akan mengurangi batasan fasa per satuan volume. Karbida ini memiliki sifat yang lebih baik dari martensit karena sifatnya yang lebih keras tetapi lebih stabil [15].

Dari data diatas dapat dilihat bahwa semakin meningkatnya temperatur tempering maka sifat mekanis seperti nilai kekerasan vickers menurun. Data terlihat nilai stabil berada pada temperatur $350^{\circ} \mathrm{C}$ dan $450^{\circ} \mathrm{C}$ setelah itu nilai variabel ini menurun drastis.

Chain-pin memiliki sifat sangat keras pada surface untuk memberikan fatique resistant dan wearability, namun diimbangi dengan sifatnya yang sangat kuat pada bagian core-nya untuk menjaga agar tidak terjadi failure (crack) karena adanya tegangan kompresi akibat perbedaan kandungan martensit antara bagian surface dan core.

\section{KESIMPULAN}

a. Chain-Pin memiliki sifat baja AISI 4340 yang telah mengalami modifikasi proses pengerasan permukaan.

b. Karakteristik awal chain-pin berupa:

i. Fasa martensit temper, ferit, sementit, juga terlihat pengerasan permukaan, korosi, porositas dan kluster martensit.

ii. Semua elemen paduan kecuali antimony, vanadium, dan niobium bersifat meningkatkan hardenability.

c. Fenomena setelah tempering berupa:

i. Ukuran batas butir chain pin yang semakin membesar dan semakin kasar.

ii. Nilai kekerasan chain pin menurun dan keuletan meningkat.

d. Dari pengamatan SEM tidak terlihat adanya retak mikro pada chain-pin. 


\section{REFERENSI}

1. Anonymous, "Conveyor Chain Installation \& Maintenance", www.renold.com, diakses: 8 Januari 2014.

2. Anonymous, "Hitachi Conveyor Chains", www.hitachi-metals-techno.com, diakses 15Maret 2014.

3. Cao Yi, Wang Zhao-dong, Kang Jian, Wudii, Wang Guo-dong, 2013, "Effects of Tempering Temperature and $\mathrm{Mo} / \mathrm{Ni}$ on Microstructures and Properties of Lath Martensitic Wear-Resistant Steels: Journal of Iron and Steel Research International," 20(4) : 70-75.

4. A.S. Aloraier, R.N. Ibrahim, J. Ghojel, 2004 ,"Eliminating post-weld heat treatment in repair welding by temper bead technique: role bead sequence in metallurgical changes: Journal of Materials Processing Technology," 153$154: 392-400$.

5. I. Tkalce, C. Azcoitia, S. Crevoiserat, D. Mari, 2004, "Tempering effects on a martensitic high carbon steel: Materials Science and Engineering, ” A 387-389: 352-356.

6. John A. Beavers, Neil G. Thompson, 2006," External Corrosion of Oil and Natural Gas Pipelines: ASM Handbook, Volume 13C, Corrosion: Environments and Industries, Ohio, USA.

7. Rashmi Ranjan Pandaa, A.M Mohanty, D.K Mohantac, 2014," Mechanical and Wear Properties of Carburized Low Carbon Steel Samples: International Journal of Multidisciplinary and Current Research," Vol.2: 109-112.

8. V.H. Baltazar Hernandez, S.S. Nayak, Y. Zhou, 2011, "Tempering of Martensite in Dual-Phase Steels and Its Effects on Softening Behavior: The Minerals, Metals \& Materials Society and ASM International," vol. 2, pp. 2373-85.

9. Chunfang Wang, Maoqiu Wang, Jie Shi, Weijun uiI and Han Dong, 2007, “ Effect of Microstructure Refinement on the Strength and Toughness of Low Alloy Martensitic Steel: J. Mater. Sci. Technol., Vol.23 No.5: 659- 664.

10. P. Wang, S.P. Lu, N.M. Xiao, D.Z. Li, Y.Y. Li, 2010," Effect of delta ferrite on impact properties of low carbon 13Cr-4Ni martensitic stainless steel: Materials Science and Engineering A," 527 (2010): 3210-3216.

11. S.K. Akaya, M. Yazicib, A. Bayramc, A. Avinc, 2009," Fatigue life behaviour of the dual-phase low carbon steel sheets: Journal of Materials Processing Technology," 209: 3358-3365.

12. Tomita, Y., 1990, "Effect of morphology of second-phase martensite on the tensile properties of Fe-0.1 C dualphase steel: J. Mater. Sci," 25:5179-5184.

13. Maleque, M.A., Poon, Y.M., Masjuki, H.H., 2004, "The effect of intercritical heat treatment on the mechanical properties of AISI 3115 steel.: J. Mater. Process. Technol,"153-154, 482-487.

14. Adnan Çalik, 2009," Effect of cooling rate on hardness and microstructure of AISI 1020, AISI 1040 and AISI 1060 Steels: International Journal of Physical Sciences, ” Vol. 4 (9):514-518.

15. S.A. Tukur, M. M. Usman, Isyaku Muhamma, N. A. Sulaiman, 2014," Effect of Tempering Temperature on Mechanical Properties of Medium Carbon Steel: International Journal of Engineering Trends and Technology," Volume 9 (15): 798- 800. 